\title{
Retinopathy of Prematurity and Assisted Reproductive Technology: Is There an Association?
}

This article was published in the following Dove Press journal: Clinical Ophthalmology

\author{
Alaa Alsammahi \\ Ahmed Basheikh (DD \\ Department of Ophthalmology, Faculty of \\ Medicine, King Abdulaziz University, \\ Jeddah, Saudi Arabia
}

Purpose: This study aimed to determine the incidence of retinopathy of prematurity (ROP) and to assess whether assisted reproductive technology (ART) is a risk factor for ROP independent of the generation of multiple births by determining the occurrence and severity of ROP and the need for treatment. We will also evaluate other risk factors associated with the development of ROP among preterm infants.

Patients and Methods: We conducted a retrospective chart review for all premature infants who were screened for ROP according to the screening guidelines of the American Academy of Ophthalmology and born at King Abdulaziz University Hospital from 2015 to 2019. In addition to ophthalmological results, data on gestational age (GA), birth weight (BW), type of pregnancy (singleton or multiple), type of conception (natural or ART), infantile factors, and maternal factors were recorded.

Results: A total of 229 preterm babies met our criteria. The mean GA at birth was 29.35 weeks. Notably, 175 neonates were conceived naturally and 54 were conceived by ART. Furthermore, 33 infants in the natural conception group were products of multiple pregnancies, as were 49 infants in the ART group. ROP was noted in 96 of 229 infants (41.92\%). No significant difference was found in the occurrence of ROP between multiple neonates in the natural and ART groups. However, ART birth babies in general were significantly associated with the development of ROP $(P=0.045)$. On multiple regression analysis, early GA, low $\mathrm{BW}$, and extended oxygen therapy were the variables most significantly associated with ROP $(P \leq 0.001)$.

Conclusion: In our sample, ART in multiple birth babies per se did not seem to be a risk factor for ROP. However, ART babies were more prone to develop ROP than natural conception birth babies, which seemed to be more severe.

Keywords: ROP, assisted conception, ART, premature, multiple births, gestational age

\section{Introduction}

Retinopathy of prematurity (ROP) is a major cause of preventable childhood blindness worldwide. If it was recognized late, it may lead to permanent visual impairment despite the advances in the management of retinal conditions. ${ }^{1}$ ROP is considered a disease of abnormal vascular development of the retina in preterm neonates, originally reported in 1942 by Goggin M. ${ }^{2}$ There are determined risk factors such as early gestational age (GA), low birth weight (BW), duration of oxygen therapy, and systemic risk factors such as anemia, sepsis, and blood transfusions that are associated with the development of ROP. ${ }^{1,3}$
Correspondence: Alaa Alsammahi Department of Ophthalmology, Faculty of Medicine, King Abdulaziz University, P.O. Box 31।35, Jeddah 21497, Saudi Arabia Tel +966590-205-901

Email samahi779@gmail.com
Clinical Ophthalmology 2021:15 227-233 in $\mathbf{P}$ 
Assisted reproductive technology (ART) of multiple birth babies comprises a big proportion of the ROP screening burden, and their number is probably going to increase as ART is increasingly used. ${ }^{4}$ However, there is a debate as to whether ART (eg in vitro fertilization [IVF]) constitutes an independent risk factor for ROP. Studies have reported inconsistent results regarding this relationship. ${ }^{5}$

The incidence of ROP in the literature from Saudi Arabia varies from $23.31 \%$ to $46.4 \% .{ }^{6,7}$ Because of the improvements in neonatal care, the incidence has been increasing in the last few years, and hence, the survival of extremely premature babies increased. ${ }^{7}$

This study aimed to determine the incidence of ROP and to assess whether ART is a risk factor for ROP independent of the generation of multiple births by determining the occurrence and severity of ROP and the need for treatment. We will also evaluate other possible risk factors associated with the development of ROP among preterm infants.

\section{Patients and Methods Design and Settings}

This study is a retrospective, observational analysis of premature infants who had been screened for ROP according to the screening guidelines of the American Academy of Ophthalmology (Infants with a BW of $\leq 1500 \mathrm{~g}$ or GA of $\leq 30$ weeks; selected infants with BW between 1500 and $2000 \mathrm{~g}$ or GA of $>30$ weeks with an unstable clinical course). All premature neonates who had been admitted to the neonatal intensive care unit (NICU) at King Abdulaziz University Hospital from January 2015 to December 2019 and had been screened for ROP by an ophthalmologist were included in the study. The study protocol was approved by the Biomedical Ethics Research Committee at King Abdulaziz University, Jeddah, Saudi Arabia. Informed consent was waived given that no personal identifiable data of any of the participants were recorded.

We reviewed the following data from the charts of these infants: type of pregnancy (singleton or multiple), type of conception (natural or ART), GA, infants factors [such as gender, birth body weight, proven sepsis, Apgar score of $<5$ at 5 minutes, phototherapy, blood transfusion, surfactant therapy, intraventricular hemorrhage, surgery (including abdominal, cardiac, and neurological surgeries) and patent ductus arteriosus], maternal history (such as maternal age, hypertension, gestational diabetes mellitus
(DM), use of antenatal steroids, and premature rupture of membranes), and duration of oxygen use. The stages of ROP and treatment for threshold ROP in multiple birth babies were recorded. GA was expressed in weeks, ignoring any additional days (eg 25 weeks 0 days to 25 weeks 6 days expressed as 25 weeks). Infants who did not survive or whose data were not complete were excluded. All these infants underwent initial fundus examination by a trained ophthalmologist in the ROP field using indirect ophthalmoscopy at 31 weeks postmenstrual age or at 4 weeks chronological age, whichever came later, and the following examination was based on the severity of ROP. The ROP classification was based on the International Classification of Retinopathy of Prematurity. ${ }^{8}$

\section{Statistical Analysis}

The data were examined for completeness and correctness. Descriptive statistics were used to present the data in tables. Comparison between ART (multiple) and natural (multiple) neonates in terms of ROP, stage, zone, and referral to treatment was done using the chi-square test. Again, the chi-square test was done to observe the association between retinopathy (yes/no) and categorical risk factors. Continuous variables were assessed for normality by the Kolmogorov-Smirnov test and the Shapiro-Wilk test, which revealed normal distribution. Independent samples $t$-test was done to compare the means of risk factors (continuous variables) in cases with ROP vs cases without ROP. $P \leq 0.05$ was considered statistically significant. The incidence rate of ROP was presented.

\section{Results}

A total of 229 premature babies were included in this study; $175(76.4 \%)$ neonates were conceived naturally and $54(23.6 \%)$ were conceived by ART (eg IVF). A total of 33 infants in the natural conception group were products of multiple pregnancies, as were 49 infants in the ART group. ROP was noted in 96 of 229 infants (41.92\%). Among 96 ROP babies, there were 67 of 175 natural conception (38.3\%) and 29 of 54 ART babies (53.7\%); a significant difference $(P=0.045)$ was found in the occurrence of ROP between 2 groups.

Among the 33 natural (multiple) deliveries, 15 (45.5\%) had ROP, and among the 49 ART (multiple) deliveries, 27 (55.1\%) had ROP. No statistically significant difference was found between the natural and ART (multiple) babies with regard to the stages of ROP and the referral to treatment. However, zone II ROP was significantly higher 
Table I Incidence of ROP in Multiple Neonates of Natural and ART

\begin{tabular}{|l|l|l|l|}
\hline & $\begin{array}{l}\text { Natural } \\
\text { (n= 33) } \\
\text { N (\%) }\end{array}$ & $\begin{array}{l}\text { ART } \\
(\mathbf{n}=49) \\
\mathbf{N}(\%)\end{array}$ & P value \\
\hline ROP & $15(45.5)$ & $27(55.1)$ & 0.391 \\
\hline $\begin{array}{c}\text { Stage I } \\
\text { II } \\
\text { III }\end{array}$ & $\begin{array}{l}13(39.4) \\
2(6.1)\end{array}$ & $\begin{array}{l}16(32.7) \\
10(20.4) \\
1(2.0)\end{array}$ & $\begin{array}{l}0.531 \\
0.065 \\
0.0598\end{array}$ \\
\hline $\begin{array}{c}\text { Zone } \\
\text { II } \\
\text { III }\end{array}$ & $\begin{array}{l}5(15.2) \\
10(30.3)\end{array}$ & $\begin{array}{l}18(36.7) \\
9(18.4)\end{array}$ & $\begin{array}{l}0.033 \\
0.209\end{array}$ \\
\hline Plus disease & $2(6.1)$ & $5(10.2)$ & 0.409 \\
\hline $\begin{array}{l}\text { Referred to } \\
\text { treatment }\end{array}$ & $4(12.1)$ & $6(12.2)$ & 0.633 \\
\hline
\end{tabular}

Abbreviation: $\mathrm{N}$, number of cases.

among the IVF (multiple) babies than their counterparts $(P=0.033)$; moreover, zone I and stages IV and V were not applicable (Table 1).

In general, $51.2 \%$ of all multiple pregnancy babies in both natural and ART groups showed a significant difference in the occurrence of ROP compared with singletons $(P=0.033)$. The following infant risk factors were significantly associated with ROP (\% of cases with ROP, $P$-value): Apgar score of $<5$ at 5 minutes $(80 \%, P=$ $0.015)$, blood transfusion $(60 \%, P=0.001)$, intraventricular hemorrhage $(62.3 \%, P<0.001)$, surgery during NICU admission $(72 \%, P=0.001)$, patent ductus arteriosus $(59.1 \%, P<0.001)$, and proven sepsis $(58 \%, P<$ $0.001)$. However, $53.4 \%$ of preterm babies who received surfactant therapy did not develop ROP compared to $46.6 \%$ of cases with ROP $(P=0.001)$. In terms of significantly associated maternal factors, more than half of premature rupture of membranes (PROM) cases $(52 \%$, $P=0.007)$ had ROP whereas the higher percentage of antenatal steroid therapy recipients (54.9\%) did not have ROP in their neonates $(P=0.048)$ (Table 2).

The study revealed a lower mean GA among ROP cases $(27.25 \pm 1.65$ vs $29.35 \pm 1.60$ weeks $)$, lower mean BW among ROP cases $(907.02 \pm 220.56$ vs $1176.24 \pm$ 224.22 grams), and higher mean number of days for oxygen therapy (56.56 \pm 33.24 vs $16.68 \pm 14.02$ days) (all $P<$ 0.001). Other studied risk factors such as maternal age, gestational DM, maternal hypertension, gender, and phototherapy were not statistically significantly associated with ROP (Table 3).

\section{Discussion}

Nowadays, ART has been increasingly used and is easily obtainable. This results in the increasing number of multiple birth babies that make up a considerable proportion of the ROP screening burden. ${ }^{4}$ Other than ROP, some studies report an increased frequency of ocular abnormalities in children born in the ART group. These malformations include Coats disease, hypoplastic optic nerve head, idiopathic optic atrophy, congenital cataract, congenital glaucoma, coloboma with microphthalmos, and retinoblastoma. ${ }^{9}$

There is a controversy as to whether ART constitutes an independent risk factor for ROP. Some authors failed to demonstrate any associations between them. In contrast, some showed a significant difference. In 2016, a retrospective study that was conducted in Turkey in a single maternity hospital analyzed the medical records of consecutive premature triplets in both natural and ART neonates who had been screened for ROP. No association was found in the presence of ROP and the mode of conception $(P=0.674) .{ }^{10}$ The first team to confirm a statistically significant association between ART and severe ROP requiring treatment in infants was from the NewYork-Presbyterian Hospital from 2002 to 2008. Their studies indicate that ART placed infants at a greater risk of treatment-requiring ROP $(P=0.0150) .{ }^{11}$ In addition, a study by Chan et al ${ }^{12}$ found that, regardless of BW, ART was associated with a nearly fivefold increased risk of severe ROP requiring treatment by using multifactor analysis $(P=0.007)$; they proved that ART seems to be an independent risk factor associated with the risk of severe ROP requiring laser.

However, some articles show only a tendency of ART of being an independent risk factor for ROP, without evidence of statistically significant results. A retrospective study performed by Barker et $\mathrm{al}^{4}$ in a tertiary neonatal unit in the United Kingdom that involved a total of 205 babies, of whom $87.3 \%$ were twins, found no significant difference between the number of babies that developed ROP in the ART and non-ART groups. However, they did not rule out a possible association because the estimated odds ratio (OR) was slightly higher in the ART babies in developing ROP.

In our study, we reported a significant difference in relation between developing ROP and ART group (OR, $1.87 ; 95 \%$ confidence interval [CI], 1.01-3.46; $P=0.045$ ). In addition, we studied the occurrence of ROP in multiple 
Table 2 Incidence of ROP by Patient Characteristics

\begin{tabular}{|c|c|c|c|c|c|}
\hline Risk Factors & $\begin{array}{l}\text { Case without ROP }(n=133) \\
\text { N (\%) }\end{array}$ & $\begin{array}{l}\text { Case with ROP }(n=96) \\
\text { N (\%) }\end{array}$ & OR & $95 \% \mathrm{Cl}$ & $P$ value \\
\hline \multicolumn{6}{|l|}{ Infant factors } \\
\hline \multicolumn{6}{|l|}{ Gender } \\
\hline Male $(\mathrm{n}=119)$ & $65(54.6)$ & $54(45.4)$ & 1.0 & $0.44-1.26$ & 0.270 \\
\hline Female $(n=110)$ & $68(61.8)$ & $42(38.2)$ & 0.74 & & \\
\hline \multicolumn{6}{|l|}{ Apgar score of $<5$ at 5 minutes } \\
\hline No $(n=219)$ & $|3|(59.8)$ & $88(40.2)$ & 1.0 & $1.24-28.70$ & 0.015 \\
\hline Yes $(n=10)$ & $2(20.0)$ & $8(80.0)$ & 5.96 & & \\
\hline \multicolumn{6}{|l|}{ Phototherapy } \\
\hline No $(n=36)$ & $19(52.8)$ & $17(47.2)$ & 1.0 & $0.38-1.58$ & 0.483 \\
\hline Yes $(n=193)$ & $114(59.1)$ & $79(40.9)$ & 0.78 & & \\
\hline \multicolumn{6}{|l|}{ Blood transfusion } \\
\hline No $(n=166)$ & $108(65.1)$ & $58(34.9)$ & 1.0 & $1.56-5.14$ & 0.001 \\
\hline Yes $(n=63)$ & $25(39.7)$ & $38(60.3)$ & 2.83 & & \\
\hline \multicolumn{6}{|l|}{ Surfactant therapy } \\
\hline No $(n=36)$ & $30(83.3)$ & $6(16.7)$ & 1.0 & $1.74-10.97$ & 0.001 \\
\hline Yes $(n=193)$ & $103(53.4)$ & $90(46.6)$ & 4.37 & & \\
\hline \multicolumn{6}{|l|}{ Intraventricular hemorrhage } \\
\hline No $(n=160)$ & $107(66.9)$ & $53(33.1)$ & 1.0 & $1.86-6.01$ & $<0.001$ \\
\hline Yes $(n=69)$ & $26(37.7)$ & $43(62.3)$ & 3.34 & & \\
\hline \multicolumn{6}{|l|}{ Proven sepsis } \\
\hline No $(n=119)$ & $87(73.1)$ & $32(26.9)$ & 1.0 & $2.17-6.59$ & $<0.001$ \\
\hline Yes $(n=110)$ & $46(41.8)$ & $64(58.2)$ & 3.78 & & \\
\hline \multicolumn{6}{|l|}{ Surgery } \\
\hline No $(n=204)$ & $126(61.8)$ & $78(38.2)$ & 1.0 & $1.66-10.40$ & 0.001 \\
\hline Yes $(n=25)$ & $7(28.0)$ & $18(72.0)$ & 4.15 & & \\
\hline \multicolumn{6}{|l|}{ Patent ductus arteriosus } \\
\hline No $(n=|4|)$ & $97(68.8)$ & $44(31.2)$ & 1.0 & I.83-5.54 & $<0.001$ \\
\hline Yes $(n=88)$ & $36(40.9)$ & $52(59.1)$ & 3.18 & & \\
\hline \multicolumn{6}{|l|}{ Conception factors } \\
\hline \multicolumn{6}{|l|}{ Type of pregnancy } \\
\hline Single $(n=147)$ & $93(63.3)$ & $54(36.7)$ & 1.0 & $1.05-3.13$ & 0.033 \\
\hline Multiple $(n=82)$ & $40(48.8)$ & $42(51.2)$ & 1.81 & & \\
\hline \multicolumn{6}{|l|}{ Type of conception } \\
\hline Natural $(n=175)$ & $108(61.7)$ & $67(38.3)$ & 1.0 & $1.01-3.46$ & 0.045 \\
\hline ART $(n=54)$ & $25(46.3)$ & $29(53.7)$ & 1.87 & & \\
\hline \multicolumn{6}{|l|}{ Maternal factors } \\
\hline \multicolumn{6}{|l|}{ Hypertension } \\
\hline No $(n=173)$ & $97(56.1)$ & $76(43.9)$ & 1.0 & $0.38-1.32$ & 0.279 \\
\hline Yes $(n=56)$ & $36(64.3)$ & $20(35.7)$ & 0.71 & & \\
\hline \multicolumn{6}{|l|}{ Premature rupture of membranes } \\
\hline No $(n=129)$ & $85(65.9)$ & $44(34.1)$ & 1.0 & $1.23-3.57$ & 0.007 \\
\hline Yes $(n=100)$ & $48(48.0)$ & $52(52.0)$ & 2.09 & & \\
\hline
\end{tabular}

(Continued) 
Table 2 (Continued).

\begin{tabular}{|c|c|c|c|c|c|}
\hline Risk Factors & $\begin{array}{l}\text { Case without ROP }(n=133) \\
N(\%)\end{array}$ & $\begin{array}{l}\text { Case with ROP }(n=96) \\
N(\%)\end{array}$ & OR & $95 \% \mathrm{Cl}$ & $P$ value \\
\hline \multicolumn{6}{|c|}{ Gestational diabetes } \\
\hline No $(n=202)$ & $114(56.4)$ & $88(43.6)$ & 1.0 & $0.23-1.30$ & 0.168 \\
\hline Yes $(n=27)$ & $19(70.4)$ & $8(29.6)$ & 0.55 & & \\
\hline \multicolumn{6}{|c|}{ Antenatal steroid therapy } \\
\hline No $(n=45)$ & $32(71.1)$ & $13(28.9)$ & 1.0 & $1.01-4.10$ & 0.048 \\
\hline Yes $(n=184)$ & I0I (54.9) & $83(45.1)$ & 2.02 & & \\
\hline
\end{tabular}

Abbreviations: $\mathrm{N}$, number of cases; $\mathrm{OR}$, odds ratio; $\mathrm{Cl}$, confidence interval.

versus single babies; it showed that $51.2 \%$ of multiple neonates had ROP with a significant difference (OR, 1.81 ; 95\% CI, 1.05-3.13; $P=0.033$ ). However, we compared only multiple babies in natural and ART groups regarding the development of ROP and its severity and the need for treatment; we found that ROP in multiple ART group tends to be more severe. More babies developed ROP in zone II $(P=0.033)$, and more babies developed stage II $(P=0.065$, which is approaching significance) in the multiple ART group compared to the multiple natural group, but no difference was found in the frequency of ROP development nor the need for treatment ( $P=0.391, P=0.633$, respectively). There is no clear

Table 3 Mean and Standard Deviation for Gestational Age, Birth Weight, Oxygen Therapy Duration, and Maternal Age in Groups of Premature Infants Screened for Retinopathy of Prematurity

\begin{tabular}{|c|c|c|c|}
\hline Risk Factors & $\begin{array}{l}\text { Case without } \\
\text { ROP } \\
(n=133)\end{array}$ & $\begin{array}{l}\text { Case with } \\
\text { ROP } \\
(n=96)\end{array}$ & $P$ value \\
\hline \multicolumn{4}{|c|}{$\begin{array}{l}\text { Gestational age } \\
\text { (weeks) }\end{array}$} \\
\hline Mean & 29.35 & 27.25 & $<0.001$ \\
\hline SD & 1.60 & 1.65 & \\
\hline \multicolumn{4}{|l|}{$\begin{array}{l}\text { Birth weight } \\
\text { (grams) }\end{array}$} \\
\hline Mean & II 76.24 & 907.02 & $<0.001$ \\
\hline SD & 224.22 & 220.56 & \\
\hline \multicolumn{4}{|c|}{$\begin{array}{l}\text { Oxygen therapy } \\
\text { (days) }\end{array}$} \\
\hline Mean & 16.68 & 56.56 & $<0.001$ \\
\hline SD & 14.02 & 33.24 & \\
\hline \multicolumn{4}{|l|}{$\begin{array}{l}\text { Maternal age } \\
\text { (years) }\end{array}$} \\
\hline Mean & 30.14 & 29.84 & 0.706 \\
\hline SD & 5.78 & 6.10 & \\
\hline
\end{tabular}

Abbreviation: SD, standard deviation. explanation in the literature regarding why the ART group is more prone to develop severe ROP. It has been suggested that this might be attributed to a genetic predisposition to develop severe ROP as part of genetic abnormalities that may occur as a result of ART. ${ }^{12}$ However, more studies regarding this point are needed.

The strongest determined risk factors for the development of ROP are GA, BW, and use of supplemental oxygen. Multiple studies found that lower BW (1500-1250 g) and younger GA ( $<31$ weeks) were strongly associated with the development of ROP. ${ }^{13-15}$ Similarly, the more oxygen concentration, prolonged duration, and prolonged mechanical ventilation, the more severe and treatment-requiring ROP is. However, despite many large randomized-controlled studies comparing different ranges for oxygen saturation, the ideal range remains debatable. ${ }^{15-17}$ This study revealed a lower mean GA, lower mean BW, and higher mean number of days for oxygen therapy among ROP cases (all $P<0.001$ ).

We found no clear association between maternal hypertension (including preeclampsia-eclampsia) or gestational $\mathrm{DM}$ and the development of ROP $(P=0.279, P=0.168$, respectively). A total of 45,082 babies in a meta-analysis on hypertensive disorders of pregnancy and ROP that included 13 cohort studies revealed no clear association. ${ }^{18}$ There are conflicting results on the association between ROP and maternal DM. Several studies report a significant association, and some do not. However, among these studies, there are many differences in DM treatment and other characteristics, which limit interpretation. $^{15}$

In this study, we reported that maternal age had no association with the occurrence of ROP $(P=0.706)$. The association between maternal age and ROP has been studied, with inconsistent results including studies showing increased incidence to one showing no association with maternal age in a large Canadian cohort study. ${ }^{15,19}$ 
Published data regarding PROM on its association with ROP risk are conflicting. PROM seems to be an independent risk factor in our study, similar to a previous Turkish singlecenter study that found an increased risk of type 1 ROP with PROM $>18$ hours. $^{20}$ However, a reported study by Lynch et $\mathrm{al}^{21}$ showed a decreased incidence of severe ROP in preterm PROM groups and indicated possible roles of perinatal therapies (such as corticosteroids) for PROM in ROP. Similarly, in our study, the higher percentage of antenatal steroid therapy recipients $(54.9 \%)$ did not have ROP $(P=$ 048), which may have - the corticosteroids - an inhibitory effect on the development of ROP. In addition, we found that preterm babies who received surfactant therapy had a lower rate of developing $\mathrm{ROP}(P=0.001)$, which may have a role - the surfactant therapy - in decreasing apnea and decreasing the duration of oxygen supplementation, which means less risk factors to develop ROP. We evaluated preterm neonates for certain clinical and demographical features and risk factors including Apgar score of $<5$ at 5 minutes, blood transfusion, intraventricular hemorrhage, patent ductus arteriosclerosis, proven sepsis, and previous surgery, and we found that these factors were significantly related to ROP. Literatures in previous several studies showed the same findings. ${ }^{14,15,22,23}$

There are some limitations in this study. First, the limited number of preterm neonates may influence the power of statistical outcomes. Second, other ROP risk factors such as necrotizing enterocolitis, apnea, race, and insulin-like growth factor 1 were not included in the study parameters. Finally, the study was retrospective, which limited the data available. Despite these limitations, this study has important implications regarding the incidence, severity, and risk factors of ROP in preterm neonates.

\section{Conclusion}

In our sample, ART in multiple birth babies per se did not seem to be a risk factor for ROP. However, ART babies were more prone to develop ROP than natural conception birth babies, which seemed to be more severe. The most significant factors associated with ROP are GA, BW, and use of oxygen therapy.

\section{Ethics Approval and Consent to Participate}

The study protocol was approved by the Biomedical Ethics Research Committee at King Abdulaziz University, Jeddah, Saudi Arabia, and was conducted according to the ethical standards of the Declaration of Helsinki (reference no 43916). Informed consent was waived given that no personal identifiable data of any of the participants were recorded.

\section{Disclosure}

The authors certify that they have no affiliations with or involvement in any organization or entity with any financial interest (such as honoraria; educational grants; participation in speakers' bureaus; membership, employment, consultancies, stock ownership, or other equity interest; and expert testimony or patent-licensing arrangements) or nonfinancial interest (such as personal or professional relationships, affiliations, knowledge, or beliefs) in the subject matter or materials discussed in this manuscript.

\section{References}

1. Alajbegovic-Halimic J, Zvizdic D, Alimanovic-Halilovic E, Dodik I, Duvnjak S. Risk factors for retinopathy of prematurity in premature born children. Med Arch. 2015;69:409-413. doi:10.5455/ medarh.2015.69.409-413

2. Goggin M, O'Keefe M. Childhood blindness in the Rep. of Ireland: a national survey. $\mathrm{Br}$ Ophthalmol. 1991;75:425.e9. doi:10.1136/ bjo.75.7.425

3. Dutta S, Narang S, Narang A, Dogra M, Gupta A. Risk factors of threshold retinopathy of prematurity. Indian Pediatr. 2004;41:665-671.

4. Barker L, Bunce C, Husain S, Adams GG. Is artificial reproductive technology a risk factor for retinopathy of prematurity independent of the generation of multiple births? Eur $J$ Ophthalmol. 2017;27:174-178. doi:10.5301/ejo.5000832

5. Trifonova K, Slaveykov K, Mumdzhiev H, Dzhelebov D. Artificial reproductive technology - a risk factor for retinopathy of prematurity. Open Access Maced J Med Sci. 2018;6:2245-2249. doi:10.3889/ oamjms.2018.448

6. Amer M, Jafri WH, Nizami AM, Shomrani AI, Al-Dabaan AA, Rashid K. Retinopathy of prematurity: are we missing any infant with retinopathy of prematurity? $\mathrm{Br} \quad \mathrm{J}$ Ophthalmol. 2012;96:1052-1055. doi:10.1136/bjophthalmol-2012-301570

7. Jacob MK, Sawardekar KP, Ayoub HG, Busaidi IA. Validation of the existing modified screening criteria for detection of all cases of Retinopathy of Prematurity in preterm babies - 11 year study from a governorate referral hospital in Oman. Saudi J Ophthalmol. 2016;30:3-8. doi:10.1016/j.sjopt.2015.12.001

8. Lad EM, Nguyen TC, Morton JM, Moshfeghi DM. Retinopathy of prematurity in the United States. Br J Ophthalmol. 2008;92:320.e5. doi:10.1136/bjo.2007.126201

9. Anteby I, Cohen E, Anteby E, BenEzra D. Ocular manifestations in children born after in vitro fertilization. Arch Ophthalmol. 2001;119:1525-1529. doi:10.1001/archopht.119.10.1525

10. Şekeroğlu MA, Hekimoğlu E, Çelik Ü, Kale Y, Baş AY. Retinopathy of prematurity in triplets. Turk J Ophthalmol. 2016;46:114-117. doi:10.4274/tjo.94815

11. Wong R, Yonekawa Y, Sun G, et al. Update: assisted conception and progression of retinopathy of prematurity. Invest Ophthalmol Vis Sci. 2009;50:3143.

12. Chan RV, Yonekawa Y, Morrison MA, et al. Association between assisted reproductive technology and advanced retinopathy of prematurity. Clin Ophthalmol. 2010;4:1385-1390. doi:10.2147/ OPTH.S15587 
13. Schaffer DB, Palmer EA, Plotsky DF, et al. Prognostic factors in the natural course of retinopathy of prematurity. The Cryotherapy for Retinopathy of Prematurity Cooperative Group. Ophthalmology. 1993;100:230-237. doi:10.1016/S0161-6420(93)31665-9

14. Thomas K, Shah PS, Canning R, Harrison A, Lee SK, Dow KE. Retinopathy of prematurity: risk factors and variability in Canadian neonatal intensive care units. $J$ Neonat Perinat Med. 2015;8:207-214. doi:10.3233/NPM-15814128

15. Kim SJ, Port AD, Swan R, Campbell JP, Chan RVP, Chiang MF. Retinopathy of prematurity: a review of risk factors and their clinical significance. Surv Ophthalmol. 2018;63:618-637. doi:10.1016/j. survophthal.2018.04.002

16. Yau GS, Lee JW, Tam VT, Liu CC, Chu BC, Yuen CY. Incidence and risk factors for retinopathy of prematurity in extreme low birth weight Chinese infants. Int Ophthalmol. 2015;35:365-373. doi:10.1007/s10792-014-9956-2

17. Enomoto H, Miki A, Matsumiya W, Honda S. Evaluation of oxygen supplementation status as a risk factor associated with the development of severe retinopathy of prematurity. Ophthalmologica. 2015;234:135-138. doi:10.1159/000433565

18. Zhu T, Zhang L, Zhao F, Qu Y, Mu D. Association of maternal hypertensive disorders with retinopathy of prematurity: a systematic review and meta-analysis. PLoS One. 2017;12:e175374. doi:10.1371/journal.pone.0175374
19. Kanungo J, James A, McMillan D, et al. Advanced maternal age and the outcomes of preterm neonates: a social paradox? Obstet Gynecol. 2011;118:872-877. doi:10.1097/AOG.0b013e31822add60

20. Ozdemır R, Sarı FN, Tunay ZO, et al. The association between respiratory tract Ureaplasma urealyticum colonization and severe retinopathy of prematurity in preterm infants $\leq 1250 \mathrm{~g}$. Eye (Lond). 2012;26:992-996. doi:10.1038/eye.2012.77

21. Lynch AM, Wagner BD, Hodges JK, et al. The relationship of the subtypes of preterm birth with retinopathy of prematurity. Am J Obstet Gynecol. 2017;217:354.e1-354.e8. doi:10.1016/j.ajog.2017.05.029

22. Ke XY, Ju RH, Zhang JQ, Chen H, Wei EX, Chen XH. Risk factors for severe retinopathy of prematurity in premature infants: a single-center study. Nan Fang Yi Ke Da Xue Xue Bao. 2011;31:1963-1967.

23. Slidsborg C, Jensen A, Forman JL, et al. Neonatal risk factors for treatment-demanding retinopathy of prematurity: a Danish national study. Ophthalmology. 2016;123:796-803. doi:10.1016/j.ophtha.2015 .12 .019
Clinical Ophthalmology

\section{Publish your work in this journal}

Clinical Ophthalmology is an international, peer-reviewed journal covering all subspecialties within ophthalmology. Key topics include: Optometry; Visual science; Pharmacology and drug therapy in eye diseases; Basic Sciences; Primary and Secondary eye care; Patient Safety and Quality of Care Improvements. This journal is indexed on PubMed

\section{Dovepress}

Central and CAS, and is the official journal of The Society of Clinical Ophthalmology (SCO). The manuscript management system is completely online and includes a very quick and fair peer-review system, which is all easy to use. Visit http://www.dovepress.com/ testimonials.php to read real quotes from published authors. 